\title{
Effects of in IL-1B/IL-1RN variants on the susceptibility to head and neck cancer in a chinese Han population
}

Yanhai Yin ${ }^{1 \dagger}$, Fen $\mathrm{Li}^{1 \dagger}$, Liangqian Tong ${ }^{2}$, Chunru Chen ${ }^{1}$ and Bo Yuan ${ }^{3^{*}}$ (D)

\begin{abstract}
Background: The study aimed to evaluate the relationship of IL-1B/IL-1RN polymorphisms to the predisposition of head and neck cancer (HNC) in a Chinese Han population.

Methods: Nine single-nucleotide polymorphisms (SNPS) in IL-1B/IL-1RN were genotyped based on Agena MassARRAY platform. Logistic regression models were used to analyze the genetic association between these SNPs and HNC risk by calculating odds ratios (ORs) and 95\% confidence intervals (Cl). Haplotype analysis were performed using Haploview program and logistic regression model.

Results: The genetic association between rs 1143643 in $I L-1 B$ and the higher risk of HNC was found $(O R=1.23,95 \%$ Cl 1.04-1.46) in the overall. IL-1RN rs 17042888 was related to a reduced risk of HNC in the subjects aged $>46$ years $(\mathrm{OR}=0.70,95 \% \mathrm{Cl}: 0.50-0.98)$ and in females $(\mathrm{OR}=0.71,95 \% \mathrm{Cl} 0.52-0.98)$, while rs 1143643 increased the predisposition of HNC among females ( $\mathrm{OR}=1.76,95 \% \mathrm{Cl} 1.13-2.74)$. Furthermore, rs 1143643 had an increased susceptibility to thyroid carcinoma $(\mathrm{OR}=1.61,95 \% \mathrm{Cl} 1.10-2.34)$. Moreover, compared with stage I-II, the frequency of IL-1RN rs452204-AG genotype was lower in patients with stage III-IV.
\end{abstract}

Conclusions: IL-1B (rs1143643) and IL-1RN (rs17042888 and rs452204) polymorphisms might be related to the individual susceptibility of HNC in the Chinese Han population. These results might help to improve the understanding of $I L-1 B$ and IL-1RN genes in the occurrence of HNC.

Keywords: Head and neck cancer, IL-1B and IL-1RN, Genetic polymorphism, Susceptibility

\section{Introduction}

Head and neck cancer (HNC) is the sixth commonly diagnosed cancer worldwide, including cancers of oral cavity, nasopharynx, larynx, and salivary glands [1]. According to the Global Cancer Statistics 2018, there were an estimated 873,734 new cases with thyroid, laryngeal and nasopharyngeal carcinoma and 208,829

\footnotetext{
*Correspondence: yuanbob@aliyun.com

${ }^{\dagger}$ Yanhai Yin and Fen Li are co-first authors

${ }^{3}$ Department of General surgery, Hainan Affiliated Hospital of Hainan Medical University, Hainan general Hospital, \#19 Xiuhua Road, Xiuying District, Haikou, Hainan Province 570311, China

Full list of author information is available at the end of the article
}

deaths from these diseases [2]. In China, HNC causes more than 2.251 million cases and 77.5 thousands deaths annually [3]. The pathogenesis of HNC has not been fully elucidated. It is known that environmental exposures to smoking and alcohol consumption are identified as the major risk factors for HNC $[4,5]$. However, not all individuals with these risk factors will eventually develop $\mathrm{HNC}$, which indicates that genetic factors may play a critical role in the carcinogenesis and progression of HNC. Cumulative evidence indicates that genetic variants contribute to the risk of HNC [6-8]. However, a large number of risk polymorphisms associated with HNC predisposition have not been discovered.

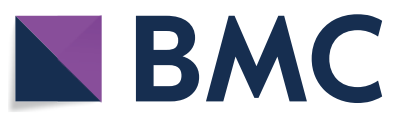

(c) The Author(s) 2021. This article is licensed under a Creative Commons Attribution 4.0 International License, which permits use, sharing, adaptation, distribution and reproduction in any medium or format, as long as you give appropriate credit to the original author(s) and the source, provide a link to the Creative Commons licence, and indicate if changes were made. The images or other third party material in this article are included in the article's Creative Commons licence, unless indicated otherwise in a credit line to the material. If material is not included in the article's Creative Commons licence and your intended use is not permitted by statutory regulation or exceeds the permitted use, you will need to obtain permission directly from the copyright holder. To view a copy of this licence, visit http://creativeco mmons.org/licenses/by/4.0/. The Creative Commons Public Domain Dedication waiver (http://creativecommons.org/publicdomain/ zero/1.0/) applies to the data made available in this article, unless otherwise stated in a credit line to the data. 
Interleukin-1 (IL-1) is an inflammatory cytokine that plays a key role in the incidence and development of tumor [9]. IL-1 family includes mainly of IL-1 $\alpha$, IL-1 $\beta$ (pro-inflammatory effect) and IL-1 receptor antagonist (IL-1RN, anti-inflammatory effect). The tumor progression driven by IL-1 is related to the promotion of angiogenesis[10]. IL- $\beta$ participates in the suppression of adaptive antitumor immune responses by regulating myeloid-derived suppressor cells [11]. Furthermore, IL-1 $\beta$ promotes epithelial to mesenchymal transition to support metastasis [12]. IL-1RN, as a natural IL-1 inhibitor, serves as a decoy target by binding to its receptor without activating signal conversion. IL-1RN can target the tumor microenvironment by interfering in IL-1 biology[13]. Several studies have reported the relationship between genetic polymorphisms of IL-1 family genes and the risk of various cancers, including breast, gastric, colorectal, and cervical cancer [14-16], but HNC has not reported.

Here, five SNPs in $I L-1 B$ and four SNPs in $I L-1 R N$ were genotyped to discover the genetic association between $I L-1 B / I L-1 R N$ polymorphisms and the risk of HNC occurrence among the Chinese Han population. The heterogeneity of associations between subgroups defined by age ( $>46$ years and $\leq 46$ years) and sex (males and females) were assessed. Furthermore, we explored the relationship of $I L-1 B / I L-1 R N$ polymorphisms with clinical features of HNC, including HNC type, stage, and lymph nodes metastasis.

\section{Materials and methods \\ Study population}

We recruited $535 \mathrm{HNC}$ patients and 538 healthy controls from Shaanxi Provincial Cancer Hospital. All participants were genetically unrelated ethnic Han Chinese population. HNC patients were diagnosed and histopathologically confirmed by two pathologists. These cases who had previous history of other cancers, chronic diseases involving vital organs, inflammation, infection, or other autoimmune diseases were excluded. HNC patients had not received chemotherapy or radiation before sample collection. Healthy controls were enrolled from the physical examination center at the same hospital. The inclusion criterion for healthy controls was no cancer history, no acute or chronic disease, and no inflammatory or immune diseases. Demographic and clinical data were obtained from the questionnaires and medical records. The study was approved by the Ethics Committee of Hainan People's Hospital and complied with the Declaration of Helsinki. All subjects gave informed consent.

\section{DNA extraction and SNPs genotyping}

Approximately $5 \mathrm{~mL}$ samples were gathered in EDTA vacutainer tubes from all subjects. Genomic DNA was extracted with GoldMag DNA Extraction Kits (GoldMag Co. Ltd, Xi'an, China) and stored at $-20{ }^{\circ} \mathrm{C}$ before genotyping. Based on the NCBI dbSNP database and 1000 Genomes Project database, candidate SNPs with the minor allele frequency (MAF) $>0.05$ low linkage disequilibrium $\left(\mathrm{r}^{2}<0.8\right)$, and the call rate $>95 \%$ were selected. Finally, nine SNPs in the $I L-1 B$ (rs1143643, rs1143630, rs1143627, rs16944 and rs1143623) and $I L-$ 1RN (rs17042888, rs315919, rs3181052 and rs452204) genes were included. The genotypes of $I L-1 B$ and $I L-1 R N$ polymorphisms were detected using Agena MassARRAY platform (Agena, San Diego, CA, USA). Primers design and data management were conducted by supporting software. The primers were presented in Additional file 1: Table S1. Approximately $10 \%$ of the study subjects were repeated genotyping for the quality control, and the results were consistent.

\section{Statistical analysis}

The characteristics of subjects were displayed as mean \pm standard deviation (SD) or frequency (percentage). The age and gender distribution between HNC patients and healthy controls were evaluated by $x^{2}$ test or sample $t$ test, respectively. The goodness of fit $\chi^{2}$ was used to test the Hardy-Weinberg equilibrium (HWE) of SNPs among controls. Logistic regression analysis adjusted for age and gender was applied to assess the genetic association between $I L-1 B / I L-1 R N$ variants and HNC risk by calculating odds ratios (ORs) and 95\% confidence intervals (CI). Linkage disequilibrium (LD) and haplotype analysis were evaluated using Haploview program and logistic regression model. SPSS 20.0 (SPSS Inc., Chicago, IL, USA), PLINK 1.0.7, Haploview 4.2 software were used for data analyses. Two-tailed $p<0.05$ was considered statistically significant.

\section{Results \\ Study population}

The characteristics of HNC patients and healthy controls were shown in Table 1 . A total of 535 patients $(46.8 \pm 15.1$ years $)$ and 538 controls $(46.9 \pm 13.8$ years $)$ were included. The ratio of male to female was $2: 3$ in the cases and controls. There was no significant difference in age and gender distribution between the two groups $(p=0.875$ and 0.908 , respectively). Among the 535 patients, 75 (14.0\%) were nasopharyngeal carcinoma, 398 (74.4\%) were thyroid cancer, 43 (8.0\%) were laryngeal carcinoma, and 19 (3.6\%) were parotid gland cancer. 
Table 1 Characteristics of patients with head and neck cancer and health controls

\begin{tabular}{llll}
\hline Variables & Cases & Control & $P$ \\
\hline N & 535 & 538 & \\
Age & & & \\
Mean \pm SD, years & $46.8 \pm 15.1$ & $46.9 \pm 13.8$ & 0.875 \\
$>46$ years & $296(55.3 \%)$ & $301(55.9 \%)$ & \\
$\leq 46$ years & $239(44.7 \%)$ & $237(44.1 \%)$ & \\
Gender & & & 0.908 \\
Male & $205(38.3 \%)$ & $208(38.7 \%)$ & \\
Female & $330(61.7 \%)$ & $330(61.3 \%)$ & \\
Lymph nodes metastasis & & & \\
Yes & $101(18.9 \%)$ & & \\
No & $82(15.3 \%)$ & & \\
Unavailable & $352(65.8 \%)$ & & \\
Stage & & & \\
I-II & $140(26.2 \%)$ & & \\
III-IV & $34(6.4 \%)$ & & \\
Unavailable & $361(67.5 \%)$ & \\
Type of head and neck cancer & & \\
Nasopharyngeal carcinoma & $75(14.0 \%)$ & \\
Thyroid cancer & $398(74.4 \%)$ & \\
Laryngeal cancer & $43(8.0 \%)$ & \\
Parotid gland carcinoma & $19(3.6 \%)$ & \\
\hline
\end{tabular}

$p$ values were calculated by $x^{2}$ test or the Student's t test

${ }^{*} p<0.05$ indicates statistical significance

The contribution of IL-1B/IL-1RN polymorphisms to the risk of HNC

The detailed information of these SNPs in $I L-1 B / I L-1 R N$ including position, MAF, the call rate of genotyping and
HWE were presented in Table 2. The MAF of these SNPs were all $>5 \%$ and the genotyping rate exceeded $99.5 \%$. Except for rs1143623 $(p<0.001)$, the genotype frequencies of other variants were in HWE among the control group. The prevalence of $I L-1 B$ rs1143643-T allele in HNC patients $(52.8 \%)$ was higher than that in controls (47.6\%). Furthermore, the genetic association was found between rs1143643 and the increased risk of HNC $(\mathrm{OR}=1.23,95 \%$ CI 1.04-1.46, $p=0.016)$.

The genotype frequency distribution of these selected SNPs in patients and controls was shown in Table 3. The frequency difference of rs1143643-TT genotype was observed between HNC patients (26.9\%) and healthy controls (22.3\%). Carriers with TT genotype had an increased susceptibility to $\mathrm{HNC}$ than $\mathrm{CC}$ genotype $(\mathrm{OR}=1.54,95 \%$ CI 1.09-2.17, $p=0.015)$. Genetic model analysis revealed that $\mathrm{rs} 1143643$ in $I L-1 B$ was related to the higher risk of $\mathrm{HNC}$ under the dominant $(\mathrm{OR}=1.38$, $95 \%$ CI 1.04-1.82, $p=0.026)$ and additive $(\mathrm{OR}=1.24$, $95 \%$ CI 1.04-1.47, $p=0.015)$ models. No significant association of other SNPs in $I L-1 B / I L-1 R N$ with $\mathrm{HNC}$ risk was observed.

\section{Stratified analysis by age and gender for the relationship of IL-1B/IL-1RN variants with HNC risk}

Stratified analysis was used to assess the heterogeneity of relationship between subgroups defined by age ( $>46$ years and $\leq 46$ years) and sex (males and females), and the results were presented in Table 4. In age stratification, we found that $I L-1 R N$ rs17042888 reduced the risk of HNC (GA vs. GG, OR $=0.70,95 \%$ CI $0.50-0.98, p=0.040$ ) in subjects aged $>46$ years. In females, the relationship between rs1143643 in $I L-1 B$ and higher predisposition

Table 2 The details of candidate SNPs in IL-1B/IL-1RN and the allele model for the association between these polymorphisms and the risk of head and neck cancer

\begin{tabular}{|c|c|c|c|c|c|c|c|c|c|c|c|}
\hline \multirow[t]{2}{*}{ Gene } & \multirow[t]{2}{*}{ SNP ID } & \multirow[t]{2}{*}{ Chr: Position } & \multirow{2}{*}{$\begin{array}{l}\text { Alleles } \\
\text { (Ref/Alt) }\end{array}$} & \multicolumn{2}{|l|}{ MAF } & \multirow[t]{2}{*}{ Call rate } & \multicolumn{3}{|l|}{ HWE } & \multirow[t]{2}{*}{ OR $(95 \% \mathrm{Cl})$} & \multirow[t]{2}{*}{$p^{b}$} \\
\hline & & & & Cases & Controls & & $\mathrm{O}(\mathrm{HET})$ & $\mathrm{E}(\mathrm{HET})$ & $p^{a}$ & & \\
\hline$I L-1 B$ & rs1143643 & $2: 112,830,725$ & $\mathrm{C} / \mathrm{T}$ & 0.528 & 0.476 & $100.0 \%$ & 0.506 & 0.499 & 0.796 & $1.23(1.04-1.46)$ & $0.016^{*}$ \\
\hline$I L-1 B$ & rs1143630 & $2: 112,834,078$ & $\mathrm{G} / \mathrm{T}$ & 0.163 & 0.161 & $100.0 \%$ & 0.273 & 0.270 & 0.874 & $1.01(0.81-1.28)$ & 0.908 \\
\hline$I L-1 B$ & rs1143627 & $2: 112,836,810$ & $G / A$ & 0.520 & 0.493 & $99.8 \%$ & 0.496 & 0.500 & 0.863 & $1.11(0.94-1.32)$ & 0.210 \\
\hline$I L-1 B$ & rs16944 & $2: 112,837,290$ & $A / G$ & 0.525 & 0.494 & $99.9 \%$ & 0.494 & 0.500 & 0.796 & $1.13(0.96-1.34)$ & 0.154 \\
\hline$I L-1 B$ & rs1143623 & $2: 112,838,252$ & $C / G$ & 0.409 & 0.417 & $100.0 \%$ & 0.403 & 0.486 & $<0.001^{*}$ & & \\
\hline$I L-1 R N$ & rs17042888 & $2: 113,104,596$ & $\mathrm{G} / \mathrm{A}$ & 0.242 & 0.271 & $100.0 \%$ & 0.413 & 0.396 & 0.383 & $0.86(0.71-1.04)$ & 0.120 \\
\hline$I L-1 R N$ & rs315919 & $2: 113,118,636$ & $\mathrm{~T} / \mathrm{G}$ & 0.375 & 0.409 & $100.0 \%$ & 0.480 & 0.483 & 0.859 & $0.87(0.73-1.03)$ & 0.105 \\
\hline$I L-1 R N$ & rs3181052 & $2: 113,128,472$ & $A / G$ & 0.392 & 0.421 & $100.0 \%$ & 0.470 & 0.488 & 0.426 & $0.89(0.75-1.05)$ & 0.165 \\
\hline$I L-1 R N$ & rs452204 & $2: 113,131,484$ & $A / G$ & 0.326 & 0.354 & $99.5 \%$ & 0.448 & 0.458 & 0.637 & $0.88(0.74-1.05)$ & 0.167 \\
\hline
\end{tabular}

SNP Single nucleotide polymorphism, MAF Minor allele frequency, HWE Hardy-Weinberg equilibrium, O(HET) Observed heterozygosity frequency, E(HET) Expected heterozygosity frequency

$p^{\text {a }}$ values were calculated by $x^{2}$ test

$p^{\mathrm{b}}$ values were calculated by logistic regression analysis with adjustments for age and gender

${ }^{*} p<0.05$ indicates statistical significance 
Table 3 The effect of genetic variants in IL-1B/IL-1RN on the susceptibility to head and neck cancer

\begin{tabular}{|c|c|c|c|c|c|c|c|}
\hline \multirow[t]{2}{*}{ Gene } & \multirow[t]{2}{*}{ SNP ID } & \multirow[t]{2}{*}{ Model } & \multirow[t]{2}{*}{ Genotype } & \multirow[t]{2}{*}{ Case } & \multirow[t]{2}{*}{ Control } & \multicolumn{2}{|c|}{ Adjusted by age and gender } \\
\hline & & & & & & OR $(95 \% \mathrm{Cl})$ & $p$ \\
\hline \multirow[t]{8}{*}{$\mathbb{L L}-1 B$} & rs1143643 & Genotype & $\mathrm{CC}$ & 114 & 146 & 1 & \\
\hline & & & $\mathrm{CT}$ & 277 & 272 & $1.30(0.97-1.75)$ & 0.080 \\
\hline & & & $\mathrm{TT}$ & 144 & 120 & $1.54(1.09-2.17)$ & $0.015^{*}$ \\
\hline & & Dominant & CC & 114 & 146 & 1 & \\
\hline & & & CT-TT & 421 & 392 & $1.38(1.04-1.82)$ & $0.026^{*}$ \\
\hline & & Recessive & CC-CT & 391 & 418 & 1 & \\
\hline & & & $\mathrm{TT}$ & 144 & 120 & $1.28(0.97-1.70)$ & 0.080 \\
\hline & & Log-additive & & & & $1.24(1.04-1.47)$ & $0.015^{*}$ \\
\hline \multirow[t]{8}{*}{$\mathbb{I L}-1 B$} & rs1143630 & Genotype & GG & 378 & 378 & 1 & \\
\hline & & & GT & 140 & 147 & $0.95(0.73-1.25)$ & 0.736 \\
\hline & & & $\mathrm{TT}$ & 17 & 13 & $1.31(0.63-2.74)$ & 0.473 \\
\hline & & Dominant & GG & 378 & 378 & 1 & \\
\hline & & & GT-TT & 157 & 160 & $0.98(0.76-1.28)$ & 0.898 \\
\hline & & Recessive & GG-GT & 518 & 525 & 1 & \\
\hline & & & $\mathrm{TT}$ & 17 & 13 & $1.33(0.64-2.76)$ & 0.449 \\
\hline & & Log-additive & & & & $1.02(0.81-1.28)$ & 0.898 \\
\hline \multirow[t]{8}{*}{$\mathbb{I L}-1 B$} & rs1143627 & Genotype & GG & 118 & 139 & 1 & \\
\hline & & & GA & 278 & 266 & $1.23(0.91-1.66)$ & 0.171 \\
\hline & & & $\mathrm{AA}$ & 139 & 131 & $1.25(0.89-1.76)$ & 0.201 \\
\hline & & Dominant & GG & 118 & 139 & 1 & \\
\hline & & & GA-AA & 417 & 397 & $1.24(0.93-1.64)$ & 0.138 \\
\hline & & Recessive & GG-GA & 396 & 405 & 1 & \\
\hline & & & $\mathrm{AA}$ & 139 & 131 & $1.09(0.82-1.43)$ & 0.559 \\
\hline & & Log-additive & & & & $1.12(0.94-1.33)$ & 0.205 \\
\hline \multirow[t]{8}{*}{$\mathbb{L L}-1 B$} & rs16944 & Genotype & $\mathrm{AA}$ & 116 & 139 & 1 & \\
\hline & & & $A G$ & 276 & 265 & $1.25(0.93-1.68)$ & 0.146 \\
\hline & & & GG & 143 & 133 & $1.29(0.92-1.81)$ & 0.146 \\
\hline & & Dominant & $\mathrm{AA}$ & 116 & 139 & 1 & \\
\hline & & & $A G-G G$ & 419 & 398 & $1.26(0.95-1.67)$ & 0.107 \\
\hline & & Recessive & AA-AG & 392 & 404 & 1 & \\
\hline & & & GG & 143 & 133 & $1.11(0.84-1.46)$ & 0.462 \\
\hline & & Log-additive & & & & $1.13(0.96-1.34)$ & 0.151 \\
\hline \multirow[t]{8}{*}{$I L-1 R N$} & rs17042888 & Genotype & GG & 310 & 281 & 1 & \\
\hline & & & $\mathrm{GA}$ & 191 & 222 & $0.78(0.61-1.00)$ & 0.053 \\
\hline & & & $\mathrm{AA}$ & 34 & 35 & $0.88(0.54-1.45)$ & 0.622 \\
\hline & & Dominant & GG & 310 & 281 & 1 & \\
\hline & & & GA-AA & 255 & 257 & $0.79(0.62-1.01)$ & 0.060 \\
\hline & & Recessive & GG-GA & 501 & 503 & 1 & \\
\hline & & & $\mathrm{AA}$ & 34 & 35 & $0.98(0.60-1.59)$ & 0.925 \\
\hline & & Log-additive & & & & $0.86(0.70-1.04)$ & 0.119 \\
\hline \multirow[t]{8}{*}{$\| L-1 R N$} & rs315919 & Genotype & $\mathrm{TT}$ & 204 & 189 & 1 & \\
\hline & & & TG & 261 & 258 & $0.94(0.72-1.22)$ & 0.627 \\
\hline & & & GG & 70 & 91 & $0.71(0.49-1.03)$ & 0.072 \\
\hline & & Dominant & TT & 204 & 189 & 1 & \\
\hline & & & TG-GG & 331 & 349 & $0.88(0.69-1.13)$ & 0.307 \\
\hline & & Recessive & TT-TG & 465 & 447 & 1 & \\
\hline & & & GG & 70 & 91 & $0.74(0.53-1.04)$ & 0.080 \\
\hline & & Log-additive & & & & $0.86(0.73-1.03)$ & 0.103 \\
\hline
\end{tabular}


Table 3 (continued)

\begin{tabular}{|c|c|c|c|c|c|c|c|}
\hline \multirow[t]{2}{*}{ Gene } & \multirow[t]{2}{*}{ SNP ID } & \multirow[t]{2}{*}{ Model } & \multirow[t]{2}{*}{ Genotype } & \multirow[t]{2}{*}{ Case } & \multirow[t]{2}{*}{ Control } & \multicolumn{2}{|c|}{ Adjusted by age and gender } \\
\hline & & & & & & OR $(95 \% \mathrm{Cl})$ & $p$ \\
\hline \multirow{8}{*}{ IL-1RN } & rs3181052 & Genotype & AA & 196 & 185 & 1 & \\
\hline & & & $A G$ & 259 & 253 & $0.97(0.74-1.26)$ & 0.799 \\
\hline & & & GG & 80 & 100 & $0.76(0.53-1.08)$ & 0.123 \\
\hline & & Dominant & AA & 196 & 185 & 1 & \\
\hline & & & AG-GG & 339 & 353 & $0.91(0.71-1.16)$ & 0.441 \\
\hline & & Recessive & $A A-A G$ & 455 & 438 & 1 & \\
\hline & & & GG & 80 & 100 & $0.77(0.56-1.06)$ & 0.113 \\
\hline & & Log-additive & & & & $0.89(0.75-1.05)$ & 0.169 \\
\hline \multirow[t]{8}{*}{ IL-1RN } & rs452204 & Genotype & AA & 237 & 226 & 1 & \\
\hline & & & $A G$ & 243 & 240 & $0.97(0.75-1.25)$ & 0.793 \\
\hline & & & GG & 52 & 70 & $0.71(0.47-1.06)$ & 0.093 \\
\hline & & Dominant & AA & 237 & 226 & 1 & \\
\hline & & & AG-GG & 295 & 310 & $0.91(0.71-1.16)$ & 0.433 \\
\hline & & Recessive & $A A-A G$ & 480 & 466 & 1 & \\
\hline & & & GG & 52 & 70 & $0.72(0.49-1.06)$ & 0.092 \\
\hline & & Log-additive & & & & $0.88(0.74-1.05)$ & 0.166 \\
\hline
\end{tabular}

SNP single nucleotide polymorphism, OR odds ratio, 95\% Cl 95\% confidence interval

$p$ values were calculated by logistic regression analysis with adjustments for age and gender

${ }^{*} p<0.05$ respects the data is statistically significant

of $\mathrm{HNC}$ was found in the allele $(\mathrm{OR}=1.31,95 \%$ CI $1.05-$ $1.62, p=0.015)$, genotype (OR $=1.76,95 \%$ CI $1.13-2.74$, $p=0.013)$, dominant $(\mathrm{OR}=1.54,95 \%$ CI 1.07-2.21, $p=0.021)$ and additive $(\mathrm{OR}=1.32,95 \% \mathrm{CI} 1.06-1.65$, $p=0.014)$ models. Whereas, IL-1RN rs17042888 was related to the lower risk of HNC among females (GA vs. $\mathrm{GG}, \mathrm{OR}=0.71,95 \%$ CI 0.52-0.98, $p=0.038$; and GA-AA vs. $\mathrm{GG}, \mathrm{OR}=0.73,95 \%$ CI $0.53-0.99, p=0.042)$.

\section{The relationship of IL-1B/IL-1RN variants with clinical features of HNC}

Furthermore, we investigated the relationship between $I L-1 B / I L-1 R N$ SNPs and the clinical features of HNC, including HNC type, stage, and lymph nodes metastasis. The effect of $I L-1 B / I L-1 R N$ variants on the susceptibility to nasopharyngeal carcinoma or thyroid carcinoma was assessed, and the results were displayed in Table 5. Rs1143643 in $I L-1 B$ increased the susceptibility to thyroid carcinoma under the allele $(\mathrm{OR}=1.26$, 95\% CI 1.05-1.52, $p=0.013)$, genotype $(\mathrm{OR}=1.61,95 \%$ CI $1.10-2.34, p=0.014)$, dominant $(\mathrm{OR}=1.42,95 \% \mathrm{CI}$ $1.04-1.94, p=0.027)$, and additive $(\mathrm{OR}=1.27,95 \% \mathrm{CI}$ $1.05-1.53, p=0.015)$ models. Moreover, the relationship between $I L-1 B / I L-1 R N$ variants and clinical stages in HNC patients was evaluated. The results displayed that compared with stage I-II, patients with stage III-IV had a lower frequency of $I L-1 R N$ rs452204-AG genotype (18.2\% vs. $48.6 \%$, OR $=0.28,95 \%$ CI $0.10-0.78, p=0.015$; Table 6). There was no significant relationship of $I L-1 B /$ $I L-1 R N$ SNPs with lymph nodes metastasis (data not shown).

\section{The association of IL-1B haplotype with HNC risk}

Additionally, haplotype analysis was performed to investigate whether $I L-1 B / I L-1 R N$ variants were in linkage disequilibrium. The result revealed that there were one block and three haplotypes (GAG, TGA and GGA) in the three $I L-1 B$ SNPs (rs1143630, rs1143627 and rs16944), as shown in Fig. 1. The haplotype frequencies of $I L-1 B$ haplotypes in the in the case group and the control group were shown in Additional file 1: Table S2. The contribution of $I L-1 B$ haplotypes to HNC susceptibility was analyzed; however, there was no significant correlation between the haplotypes of $I L-1 B$ and HNC risk $(p>0.05)$ (Additional file 2).

\section{Discussion}

In this study, the genetic association of eight SNPs in $I L-1 B / I L-1 R N$ with HNC susceptibility was evaluated, which displayed that $I L-1 B$ rs1143643 increased the risk of $\mathrm{HNC}$ in the overall. $I L-1 R N$ rs17042888 was associated with a reduced risk of $\mathrm{HNC}$ in subjects aged $>46$ years 
Table 4 Stratification by age and gender for the effect of genetic variants in IL-1B/IL-1RN on the susceptibility of head and neck cancer

\begin{tabular}{|c|c|c|c|c|c|c|c|c|c|c|c|}
\hline Gene & SNP ID & Model & Genotype & Case & Control & OR $(95 \% \mathrm{Cl})$ & $p$ & Case & Control & OR $(95 \% \mathrm{Cl})$ & $p$ \\
\hline \multicolumn{4}{|c|}{ Age stratification } & \multicolumn{4}{|c|}{$>46$ years } & \multicolumn{4}{|c|}{$\leq 46$ years } \\
\hline \multirow[t]{10}{*}{$I L-1 R N$} & rs17042888 & Allele & G & 449 & 439 & 1 & & 362 & 345 & 1 & \\
\hline & & & A & 143 & 163 & $0.86(0.66-1.11)$ & 0.248 & 116 & 129 & $0.86(0.64-1.15)$ & 0.298 \\
\hline & & Genotype & GG & 176 & 157 & 1 & & 134 & 124 & 1 & \\
\hline & & & GA & 97 & 125 & $0.70(0.50-0.98)$ & $0.040^{*}$ & 94 & 97 & $0.91(0.63-1.33)$ & 0.627 \\
\hline & & & $\mathrm{AA}$ & 23 & 19 & $1.07(0.56-2.05)$ & 0.831 & 11 & 16 & $0.64(0.29-1.44)$ & 0.285 \\
\hline & & Dominant & GG & 176 & 157 & 1 & & 134 & 124 & 1 & \\
\hline & & & GA-AA & 120 & 144 & $0.75(0.54-1.04)$ & 0.080 & 105 & 113 & $0.87(0.61-1.25)$ & 0.463 \\
\hline & & Recessive & GG-GA & 273 & 282 & 1 & & 228 & 221 & 1 & \\
\hline & & & $\mathrm{AA}$ & 23 & 19 & $1.24(0.66-2.32)$ & 0.510 & 11 & 16 & $0.67(0.30-1.48)$ & 0.321 \\
\hline & & Log-additive & & & & $0.86(0.67-1.12)$ & 0.262 & & & $0.86(0.64-1.16)$ & 0.322 \\
\hline \multicolumn{4}{|c|}{ Gender stratification } & \multicolumn{4}{|l|}{ Males } & \multicolumn{4}{|c|}{ Females } \\
\hline \multirow[t]{10}{*}{$\mathbb{I L}-1 B$} & rs1143643 & Allele & C & 203 & 219 & 1 & & 302 & 346 & 1 & \\
\hline & & & $\mathrm{T}$ & 207 & 198 & $1.12(0.85-1.48)$ & 0.406 & 358 & 314 & $1.31(1.05-1.62)$ & $0.015^{*}$ \\
\hline & & Genotype & $\mathrm{CC}$ & 50 & 57 & 1 & & 64 & 89 & 1 & \\
\hline & & & $\mathrm{CT}$ & 103 & 107 & $1.13(0.71-1.81)$ & 0.600 & 174 & 168 & $1.44(0.98-2.12)$ & 0.063 \\
\hline & & & $\mathrm{TT}$ & 52 & 47 & $1.26(0.73-2.19)$ & 0.401 & 92 & 73 & $1.76(1.13-2.74)$ & $0.013^{*}$ \\
\hline & & Dominant & CC & 50 & 57 & 1 & & 64 & 89 & 1 & \\
\hline & & & CT-TT & 155 & 151 & $1.17(0.76-1.83)$ & 0.476 & 266 & 241 & $1.54(1.07-2.21)$ & $0.021^{*}$ \\
\hline & & Recessive & CC-CT & 153 & 161 & 1 & & 238 & 257 & 1 & \\
\hline & & & $\mathrm{TT}$ & 52 & 47 & $1.16(0.74-1.83)$ & 0.510 & 92 & 73 & $1.36(0.96-1.94)$ & 0.086 \\
\hline & & Log-additive & & & & $1.13(0.86-1.48)$ & 0.401 & & & $1.32(1.06-1.65)$ & $0.014^{*}$ \\
\hline \multirow[t]{10}{*}{$I L-1 R N$} & rs17042888 & Allele & G & 306 & 306 & 1 & & 505 & 478 & 1 & \\
\hline & & & $A$ & 104 & 110 & $0.95(0.69-1.29)$ & 0.724 & 155 & 182 & $0.81(0.63-1.03)$ & 0.088 \\
\hline & & Genotype & GG & 115 & 112 & 1 & & 195 & 169 & 1 & \\
\hline & & & GA & 76 & 82 & $0.90(0.60-1.36)$ & 0.624 & 115 & 140 & $0.71(0.52-0.98)$ & $0.038^{*}$ \\
\hline & & & AA & 14 & 14 & $0.97(0.44-2.13)$ & 0.939 & 20 & 21 & $0.83(0.43-1.58)$ & 0.571 \\
\hline & & Dominant & GG & 115 & 112 & 1 & & 195 & 169 & 1 & \\
\hline & & & GA-AA & 90 & 96 & $0.91(0.62-1.35)$ & 0.646 & 135 & 161 & $0.73(0.53-0.99)$ & $0.042^{*}$ \\
\hline & & Recessive & GG-GA & 191 & 194 & 1 & & 310 & 309 & 1 & \\
\hline & & & $A A$ & 14 & 14 & $1.01(0.47-2.18)$ & 0.977 & 20 & 21 & $0.95(0.51-1.80)$ & 0.884 \\
\hline & & Log-additive & & & & $0.95(0.69-1.29)$ & 0.721 & & & $0.80(0.63-1.03)$ & 0.087 \\
\hline
\end{tabular}

SNP single nucleotide polymorphism, OR odds ratio, 95\% Cl 95\% confidence interval

$p$ values were calculated by logistic regression analysis with adjustments for age and gender

${ }^{*} p<0.05$ respects the data is statistically significant

and in females. The relationship between rs1143643 and higher predisposition of HNC was found among females. Furthermore, rs1143643 was associated with increased susceptibility of thyroid carcinoma, not nasopharyngeal carcinoma. Moreover, compared with stage I-II, patients with stage III-IV had a lower frequency of $I L-1 R N$ rs452204-AG genotype. This is the first study to assess the effect of $I L-1 B / I L-1 R N$ SNPs on HNC predisposition.

IL-1 plays a role in the genesis and progression of tumors, including promoting tumor angiogenesis, driving non-resolving inflammatory microenvironment, inducing myeloid-derived suppressor cells, activating
IL-1-IL-17 pathway, and maintaining the activity of immunosuppressive tumor-associated macrophage [9]. Pervious study reported the relation between IL1-RN and the degree of HNC differentiation [17]. Overexpression of IL-1 activity increases the growth and metastasis of HNC [18]. IL1 was identified to be associated with the increased anti-tumor efficacy of cetuximab in HNC [19]. The intervention of IL-1 $\beta$-CCL22-CCR4 signaling axis might provide a new treatment strategy for HNC [20]. These studies supported that IL-1 had a crucial role in the occurrence and development of HNC. Here, we 
Table 5 The effect of genetic variants in IL-1B/IL-1RN on the susceptibility of nasopharyngeal carcinoma and thyroid carcinoma

\begin{tabular}{|c|c|c|c|c|c|c|c|c|c|c|}
\hline \multirow[t]{2}{*}{ Gene } & \multirow[t]{2}{*}{ SNP ID } & \multirow[t]{2}{*}{ Model } & \multirow[t]{2}{*}{ Genotype } & \multirow[t]{2}{*}{ Control } & \multicolumn{3}{|c|}{ Nasopharyngeal carcinoma } & \multicolumn{3}{|c|}{ Thyroid carcinoma } \\
\hline & & & & & Case & OR $(95 \% \mathrm{Cl})$ & $p$ & Case & OR $(95 \% \mathrm{CI})$ & $p$ \\
\hline \multirow[t]{10}{*}{$I L-1 B$} & rs1143643 & Allele & C & 564 & 87 & 1 & & 371 & 1 & \\
\hline & & & $\mathrm{T}$ & 512 & 72 & $1.02(0.72-1.43)$ & 0.924 & 425 & $1.26(1.05-1.52)$ & $0.013^{*}$ \\
\hline & & Genotype & $\mathrm{CC}$ & 146 & 20 & 1 & & 82 & 1 & \\
\hline & & & $\mathrm{CT}$ & 272 & 38 & $1.03(0.51-2.07)$ & 0.946 & 207 & $1.61(1.1-2.34)$ & $0.014^{*}$ \\
\hline & & & $\mathrm{TT}$ & 120 & 17 & $1.06(0.59-1.91)$ & 0.841 & 109 & $1.34(0.97-1.86)$ & 0.080 \\
\hline & & Dominant & $\mathrm{CC}$ & 146 & 20 & 1 & & 82 & 1 & \\
\hline & & & CT-TT & 392 & 55 & $1.05(0.60-1.83)$ & 0.863 & 316 & $1.42(1.04-1.94)$ & $0.027^{*}$ \\
\hline & & Recessive & CC-CT & 418 & 58 & 1 & & 289 & 1 & \\
\hline & & & $\mathrm{TT}$ & 120 & 17 & $0.99(0.55-1.77)$ & 0.961 & 109 & $1.31(0.97-1.78)$ & 0.078 \\
\hline & & Log-additive & & & & $1.01(0.72-1.44)$ & 0.936 & & $1.27(1.05-1.53)$ & $0.015^{*}$ \\
\hline
\end{tabular}

SNP single nucleotide polymorphism, OR odds ratio, 95\% Cl 95\% confidence interval

$p$ values were calculated by logistic regression analysis with adjustments for age and gender

${ }^{*} p<0.05$ respects the data is statistically significant

Table 6 Relationship of clinical stage with IL-1B/IL-1RN variants in head and neck cancer patients

\begin{tabular}{|c|c|c|c|c|c|c|c|}
\hline \multirow[t]{2}{*}{ Gene } & \multirow[t]{2}{*}{ SNP ID } & \multirow[t]{2}{*}{ Model } & \multirow[t]{2}{*}{ Genotype } & \multicolumn{4}{|c|}{ Head and neck cancer } \\
\hline & & & & III-IV & I-II & OR $(95 \% \mathrm{Cl})$ & $p$ \\
\hline \multirow[t]{10}{*}{ IL-IRN } & rs452204 & Allele & $A$ & 48 & 190 & 1 & \\
\hline & & & G & 18 & 90 & $0.79(0.44-1.44)$ & 0.442 \\
\hline & & Genotype & AA & 21 & 61 & 1 & \\
\hline & & & $A G$ & 6 & 68 & $0.28(0.10-0.78)$ & $0.015^{*}$ \\
\hline & & & GG & 6 & 11 & $1.71(0.53-5.47)$ & 0.369 \\
\hline & & Dominant & AA & 21 & 61 & 1 & \\
\hline & & & $A G-G G$ & 12 & 79 & $0.49(0.22-1.13)$ & 0.094 \\
\hline & & Recessive & $A A-A G$ & 27 & 129 & 1 & \\
\hline & & & GG & 6 & 11 & $2.70(0.87-8.37)$ & 0.085 \\
\hline & & Log-additive & & & & $0.87(0.47-1.61)$ & 0.662 \\
\hline
\end{tabular}

SNP single nucleotide polymorphism, OR odds ratio, 95\% Cl 95\% confidence interval

$p$ values were calculated by logistic regression analysis with adjustments for age and gender

${ }^{*} p<0.05$ respects the data is statistically significant

investigated the contribution of $I L-1 B / I L-1 R N$ variants to $\mathrm{HNC}$ risk among Chinese Han population for the first time.

IL1B rs1143643 $\mathrm{C}>\mathrm{T}$, located in the intron region, might have a functional effect on the selected eQTL hits, enhancer histone marks, motifs changed, and DNAse, as predicted by HaploReg v4.1. Previously, IL1B rs1143643 was related to various diseases, such as neonatal sepsis, pediatric asthma, and cervical cancer [21-23]. Here, we found that the prevalence of $I L-1 B$ rs1143643-T allele in HNC patients $(52.8 \%)$ was higher than that in the controls (47.6\%). IL-1B rs 1143643 increased the risk of HNC under the multiple models. Considering that age and gender are risk factors for HNC [24], we conducted a further stratified analysis to assess the heterogeneity of the association between subgroups defined by age and sex. We found that $I L-1 R N$ rs17042888 might be a protective factor for $\mathrm{HNC}$ in subjects aged $>46$ years and in females. Similarly, a study revealed that $I L-1 R N$ rs17042888 could reduce the risk of thyroid carcinoma [25]. Moreover, the relationship between rs1143643 and higher predisposition of HNC was found among females. These results indicated that the genetic association between $I L-1 B / I L$ IRN SNPs and HNC predisposition might be related to age and gender.

Furthermore, the correlation between $I L-1 B / I L-1 R N$ variants and the clinical features of $\mathrm{HNC}$, including HNC type, stage, and lymph nodes metastasis was also 


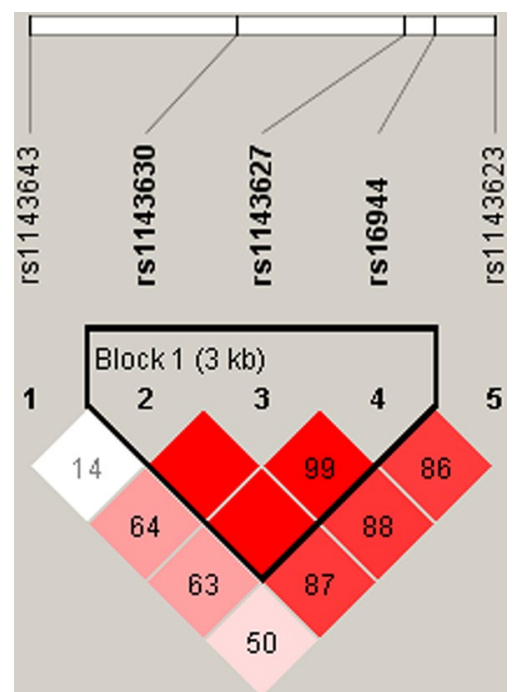

Fig. 1 Linkage disequilibrium (LD) analysis of IL-1B SNPs measured by DC. The block structure was assessed using Haploview 4.2 software

evaluated. IL-1 $\beta$ exerts strong antitumor effects on thyroid carcinoma by inhibiting proliferation and invasiveness [26]. IL1B rs1143643 was related to lymph node metastasis of papillary thyroid carcinoma in Korean patients [27]. We found that rs1143643 was associated with increased susceptibility to thyroid carcinoma. Moreover, compared with stage I-II, patients with stage III-IV had a lower frequency of $I L-1 R N$ rs452204-AG genotype. However, we did not find a significant relationship between $I L-1 B / I L-1 R N$ variants and lymph node metastasis of HNC.

Nonetheless, some potential limitations cannot be ignored. First, the sample size of laryngeal carcinoma and parotid gland cancer was relatively small, therefore the correlation between $I L-1 B / I L-1 R N$ SNPs and the risk of laryngeal carcinoma and parotid gland cancer was not analyzed. Second, the subjects in this study were recruited from one hospital, so the inherent selection bias cannot be completely excluded. Here, we matched the age, gender, and frequency between cases and controls, and adjusted for potential confounding factors to minimize the bias. Third, due to the incomplete information, the interaction between environmental and genetic factors in the risk of HNC was not assessed in this study.

\section{Conclusions}

In conclusion, our results indicated that $I L-1 B$ (rs1143643) and $I L-1 R N$ (rs17042888 and rs452204) polymorphisms might contribute to the individual predisposition to HNC in Chinese Han population. These results might help to enhance the understanding of $I L-1 B$ and $I L-1 R N$ genes in the occurrence and development of HNC. Further studies on various different ethnic groups and a large sample sizes are required to validate our findings.

\section{Supplementary Information}

The online version contains supplementary material available at https://doi. org/10.1186/s12935-021-01750-0.

Additional file1: Table S1. The detail of PCR primers and UEP sequence for genetic variants in IL-1B/IL-1RN. Table S2. Haplotype frequencies of IL-1B gene and the correlation with the risk of head and neck cancer. Additional file 2: The results of genotype.

\section{Acknowledgements}

The authors thank all participants and volunteers in this study.

\section{Authors' contributions}

The work was carried out in collaboration between all authors. YY and FL carried out the molecular genetic studies and drafted the manuscript. LT and CC designed the methods and experiments, performed the SNP genotyping experiments, the statistical analyses and interpreted the results. BY conceived of the study, worked on associated data collection and their interpretation, participated in the design and coordination of the study, and funded the study. All authors read and approved the final manuscript.

\section{Funding}

No.

Availability of data and materials

The datasets used during the current study are available from the corresponding author on a reasonable request.

\section{Ethics approval and consent to participate}

The study was approved by the Ethics Committee of Hainan People's Hospital, and complied with the Declaration of Helsinki. Informed consent was given by all the subjects.

\section{Consent for publication}

All authors declare that they consent for publication.

\section{Competing interests}

All authors declare that they have no competing interests.

\section{Author details}

${ }^{1}$ Department of Nuclear medicine, Hainan Affiliated Hospital of Hainan Medical University, Hainan general Hospital, Haikou, Hainan Province, China. ${ }^{2}$ Department of Nuclear medicine, Haikou general Hospital, Haikou, Hainan Province, China. ${ }^{3}$ Department of General surgery, Hainan Affiliated Hospital of Hainan Medical University, Hainan general Hospital, \#19 Xiuhua Road, Xiuying District, Haikou, Hainan Province 570311, China.

Received: 10 November 2020 Accepted: 2 January 2021

Published online: 20 January 2021

References

1. Cohen N, Fedewa S, Chen AY. Epidemiology and Demographics of the Head and Neck Cancer Population. Oral Maxillofacial Surgery Clinics North America. 2018;30(4):381-95.

2. Bray F, Ferlay J, Soerjomataram I, et al. Global cancer statistics 2018: GLOBOCAN estimates of incidence and mortality worldwide for 36 cancers in 185 countries. Cancer J Clin. 2018;68(6):394-424. 
3. Chen W, Zheng R, Baade PD, et al. Cancer statistics in China, 2015. Cancer J Clin. 2016;66(2):115-32.

4. Zhou J, Michaud DS, Langevin SM, et al. Smokeless tobacco and risk of head and neck cancer: evidence from a case-control study in New England. Int J cancer. 2013;132(8):1911-7.

5. Kawakita D, Matsuo K. Alcohol and head and neck cancer. Cancer Metastasis Rev. 2017;36(3):425-34

6. Li L, Zhang ZT. Genetic Association between NFKBIA and NFKB1 Gene Polymorphisms and the Susceptibility to Head and Neck Cancer: A MetaAnalysis. Disease Markers. 2019;2019:6523837.

7. Dylawerska A, Barczak W, Wegner A, et al. Association of DNA repair genes polymorphisms and mutations with increased risk of head and neck cancer: a review. Med Oncol\&nbsp; 2017;34(12):197.

8. Kiczmer P, Prawdzic Seńkowska A, Strzelczyk JK, et al. The role of MGMT polymorphisms rs 12917 and rs 11016879 in head and neck cancer risk and prognosis. Acta Biochim Pol. 2018;65(1):87-92.

9. Mantovani A, Barajon I, Garlanda C. IL-1 and IL-1 regulatory pathways in cancer progression and therapy. Immunological Rev. 2018;281(1):57-61

10. Voronov E, Carmi Y, Apte RN. The role IL-1 in tumor-mediated angiogenesis. Front Physiol. 2014;5:114.

11. Elkabets M, Ribeiro VS, Dinarello CA, et al. IL-1 $\beta$ regulates a novel myeloidderived suppressor cell subset that impairs NK cell development and function. Eur J Immunol. 2010;40(12):3347-57.

12. Voronov E, Dotan S, Krelin Y, et al. Unique Versus Redundant Functions of IL-1 $a$ and IL-1 $\beta$ in the Tumor Microenvironment. Front\&nbsp; Immunol. 2013:4:177.

13. Voronov E, Apte RN. Targeting the Tumor Microenvironment by Intervention in Interleukin-1 Biology. Curr Pharm Design. 2017;23(32):4893-905.

14. Wang J, Shi Y, Wang G, et al. The association between interleukin-1 polymorphisms and their protein expression in Chinese Han patients with breast cancer. Mol Genet Genom Med. 2019:7(8):e804.

15. Abbasian MH, Abbasi B, Ansarinejad N, et al. Association of interleukin-1 gene polymorphism with risk of gastric and colorectal cancers in an Iranian population. Iranian J Immunol. 2018;15(4):321-8.

16. Zidi S, Sghaier I, Zouidi F, et al. Interleukin-1 Gene Cluster Polymorphisms and its Haplotypes may Predict the Risk to Develop Cervical Cancer in Tunisia. Pathology Oncol Res. 2015;21(4):1101-7.

17. Westin U, Nyström M, Ljungcrantz I, et al. The presence of elafin, SLPI, ILI-RA and STNFalpha RI in head and neck squamous cell carcinomas and their relation to the degree of tumour differentiation. Mediat Inflamm. 2002;11(1):7-12.

18. von Biberstein SE, Spiro JD, Lindquist $R$, et al. Interleukin-1 receptor antagonist in head and neck squamous cell carcinoma. Archives\&nbsp; Otolaryngol Head Neck Surg. 1996;122(7):751-9.

19. Espinosa-Cotton M, Rodman lii SN, Ross KA, et al. Interleukin-1 alpha increases anti-tumor efficacy of cetuximab in head and neck squamous cell carcinoma. J Immunother Cancer. 2019;7(1):79.

20. Huang YH, Chang CY, Kuo YZ, et al. Cancer-associated fibroblast-derived interleukin-1 $\beta$ activates protumor $C-C$ motif chemokine ligand 22 signaling in head and neck cancer. Cancer Sci. 2019;110(9):2783-93.

21. Mustarim M, Yanwirasti Y, Jamsari J, et al. Association of Gene Polymorphism of Bactericidal Permeability Increasing Protein Rs4358188, Cluster of Differentiation 14 Rs2569190, Interleukin $1 \beta$ Rs 1143643 and Matrix Metalloproteinase-16 Rs 2664349 with Neonatal Sepsis. Open Access Macedonian J Med Sci. 2019;7(17):2728-33.

22. Sobkowiak P, Wojsyk-Banaszak I, Kowalewska M, et al. Interleukin $1 \beta$ polymorphism and serum level are associated with pediatric asthma. Pediatric Pulmonol. 2017;52(12):1565-71.

23. Pontillo A, Bricher P, Leal VN, et al. Role of inflammasome genetics in susceptibility to HPV infection and cervical cancer development. Journal\&nbsp;Med Virol. 2016;88(9):1646-51.

24. Rettig EM, D'Souza G. Epidemiology of head and neck cancer. Surg Oncol Clin N Am. 2015;24(3):379-96.

25. Li H, Wu Y, Zhao R, et al: IL-1RN gene polymorphisms reduces thyroid cancer risk in Chinese Han population. 2020.

26. Yip I, Pang XP, Berg $L$, et al. Antitumor actions of interferon-gamma and interleukin-1 beta on human papillary thyroid carcinoma cell lines. J Clin Endocrinol Metab. 1995;80(5):1664-9.

27. Ban JY, Kim MK, Park SW, et al. Interleukin-1 beta polymorphisms are associated with lymph node metastasis in Korean patients with papillary thyroid carcinoma. Immunol Investig. 2012;41 (8):888-905.

\section{Publisher's note}

Springer Nature remains neutral with regard to jurisdictional claims in published maps and institutional affiliations.
Ready to submit your research? Choose BMC and benefit from:

- fast, convenient online submission

- thorough peer review by experienced researchers in your field

- rapid publication on acceptance

- support for research data, including large and complex data types

- gold Open Access which fosters wider collaboration and increased citations

- maximum visibility for your research: over 100M website views per year

At BMC, research is always in progress.

Learn more biomedcentral.com/submissions 